\title{
Micro x-ray fluorescence analysis of trace element distribution in frozen hydrated HeLa cells at the P06 beamline at Petra III
}

Cite as: Biointerphases 16, 011004 (2021); https://doi.org/10.1116/6.0000593

Submitted: 31 August 2020 • Accepted: 04 January 2021 • Published Online: 27 January 2021

(iD) Christoph Rumancev, (D) Tobias Vöpel, Susan Stuhr, et al.
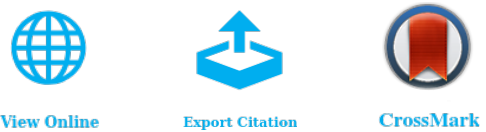

\section{ARTICLES YOU MAY BE INTERESTED IN}

Magnetron sputtered magnesium-based thin film metallic glasses for bioimplants

Biointerphases 16, 011005 (2021); https://doi.org/10.1116/6.0000535

Effect of ambient temperature on respiratory tract cells exposed to SARS-CoV-2 viral mimicking nanospheres-An experimental study

Biointerphases 16, 011006 (2021); https://doi.org/10.1116/6.0000743

Bacillus subtilis extracellular polymeric substances conditioning layers inhibit Escherichia coli adhesion to silicon surfaces: A potential candidate for interfacial antifouling additives

Biointerphases 16, 011003 (2021); https://doi.org/10.1116/6.0000737

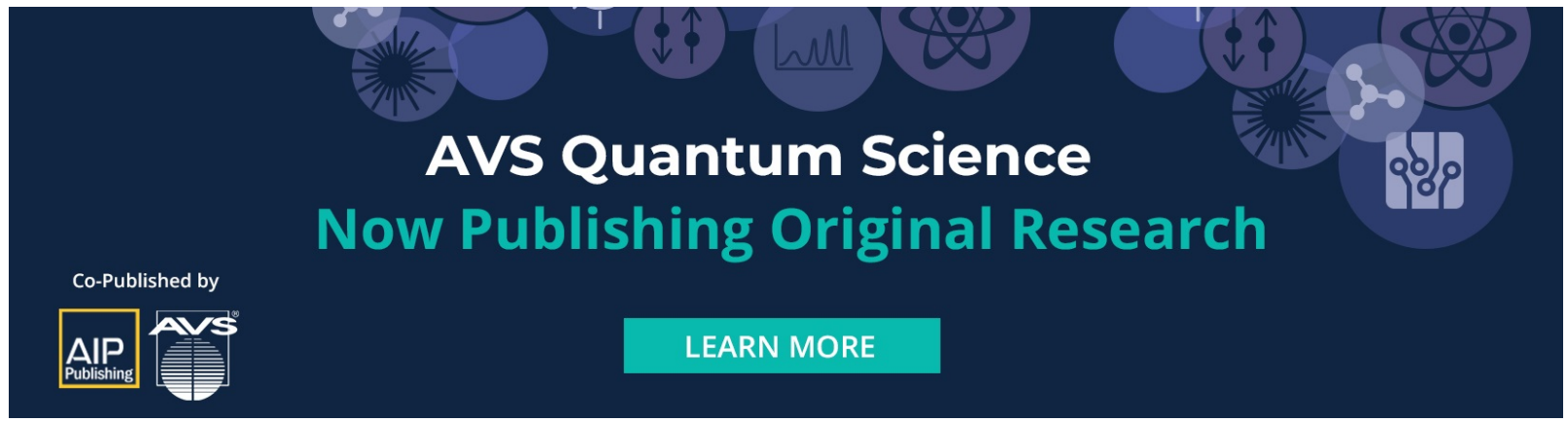




\title{
Micro x-ray fluorescence analysis of trace element distribution in frozen hydrated HeLa cells at the P06 beamline at Petra III
}

\author{
Cite as: Biointerphases 16, 011004 (2021); doi: 10.11 16/6.0000593 \\ Submitted: 31 August 2020 - Accepted: 4 January 2021 . \\ Published Online: 27 January 2021
}

Christoph Rumancev, ${ }^{1}$ (D Tobias Vöpel, ${ }^{2}$ (D) Susan Stuhr, ${ }^{1}$ Andreas von Gundlach, ${ }^{7}$ Tobias Senkbeil, ${ }^{1}$

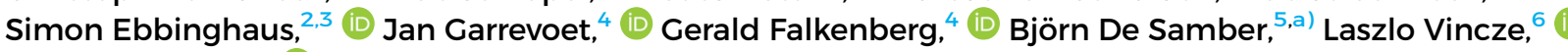
Axel Rosenhahn, ${ }^{7}$ (D) and Walter Schroeder ${ }^{4, b)}$

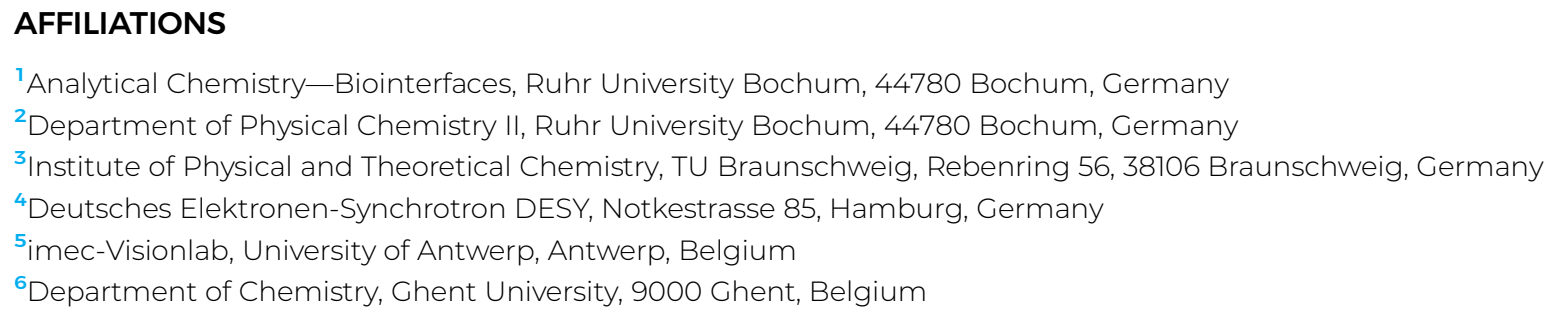

\begin{abstract}
$\mathrm{X}$-ray fluorescence analysis enables the study of trace element distributions in biological specimens. When this analysis is done under cryogenic conditions, cells are cryofixed as closely as possible to their natural physiological state, and the corresponding intracellular elemental densities can be analyzed. Details about the experimental setup used for analysis at the P06 beamline at Petra III, DESY and the used cryo-transfer system are described in this work. The system was applied to analyze the elemental distribution in single HeLa cells, a cell line frequently used in a wide range of biological applications. Cells adhered to silicon nitride substrates were cryoprotected within an amorphous ice matrix. Using a continuous scanning scheme and a KB x-ray focus, the distribution of elements in the cells was studied. We were able to image the intracellular potassium and zinc levels in HeLa cells as two key elements relevant for the physiology of cells.
\end{abstract}

Published under license by AVS. https://doi.org/10.1116/6.0000593

\section{INTRODUCTION}

Due to excellent spatial resolution and high sensitivity, $\mathrm{x}$-ray fluorescence (XRF) microscopy at third generation synchrotron sources offers the opportunity to investigate trace element distributions in biological samples with high spatial resolution and penetration depth. ${ }^{1,2}$ A key feature of the technique is its ability to provide spatially resolved information on elemental distribution in specimens with bulk sensitivities. This technique has been applied to study a wide range of materials, including biological samples with relevance to environmental science or medicine. ${ }^{3-9}$ In developmental biology, x-ray fluorescence imaging allows an understanding of calcium phosphate transformations into crystalline minerals in zebrafish fin rays. ${ }^{10} \mathrm{~A}$ combination of $\mathrm{x}$-ray fluorescence analysis with ptychography adds high-resolution electron density information to the analytical technique, as demonstrated for an analysis of green algae. ${ }^{11}$ Cryogenic preparation of samples minimizes changes in intracellular elemental distributions and reduces radiation damage. ${ }^{12}$ For frozen hydrated neutrophils, the change in intracellular element concentration during extracellular trap formation could be determined at the ID16 beamline of the ESRF. ${ }^{13}$ The uptake of nanoparticles by cells was visualized using the Bionanoprobe at the APS. ${ }^{14}$ An enhanced depth resolution can be achieved either by confocal $\mathrm{XRF}^{15-17}$ or by $3 \mathrm{D} \mathrm{x}$-ray fluorescence tomography. ${ }^{18-20}$ Particularly, for an analysis of single cells, $\mathrm{x}$-ray fluorescence microscopy provides a useful addition to the toolbox of molecular biology as the elemental distribution inside 
cryogenically fixed cells, e.g., after treatment with drugs, ${ }^{4-6,21,22}$ can be imaged without the use of labels. This technique is also very useful to study the distribution of elements in the organelles of cells after administering cytostatic drugs.

Information on intracellular elemental distributions is highly important to understand metabolic cellular processes and alterations of the intracellular element concentrations as they are associated with a range of diseases. ${ }^{23-27}$ Highly hydrated cellular systems have a low spatial density of elements due to the low metal concentrations in cells in conjunction with a relatively shallow thickness (several $\mu \mathrm{m}$ ). Frequently, cells are dehydrated prior to the measurements in vacuum. It is well known that chemical fixation and drying can affect the content and distribution of the different chemical elements in biological samples and, in particular, levels of weakly bound elements like $\mathrm{K}$ could be decreased. ${ }^{28}$ Due to the fact that $\mathrm{K}, \mathrm{Cl}$, and $\mathrm{Ca}$ are involved in membrane transport processes with high diffusion constants, they are particularly prone to be affected by chemical fixation. ${ }^{28-30}$ Also, the concentration of intracellular components like carbohydrates, phosphates, lipids, and, in particular, proteins that bind to metal ions, can be altered. ${ }^{28,30,31}$ Even washing steps with phosphate buffered saline (PBS) buffer can affect the concentration of such compounds. ${ }^{30}$ In combination with cryogenic fixation, ${ }^{32} \mathrm{XRF}$ allows the acquisition of high resolution 2D images of local element distributions as close as possible to the native state and with minimal radiation damage. As cryogenic micro- and nanoprobe-XRF requires neither chemical fixation nor chemical staining, samples are maintained in a physiologically relevant environment as close to their natural state as possible throughout the measurement. As a result, the native hydrated state of elemental distributions is highly conserved. Jin et al. ${ }^{33}$ performed a synchrotron XRF study in which different fixation protocols were tested and the elemental contents of cells were compared. They showed that particularly $\mathrm{K}$ and $\mathrm{Cl}$ are affected by chemical fixation. The cryogenic samples in their experiment were investigated under $100 \mathrm{~K}$ in a cryojet to conserve the amorphous ice layer.

In this work, we recorded maps of the element distribution in cryogenically fixed HeLa cells using a cryo-vacuum chamber in combination with a cryo-transfer system at the P06 beamline of Petra III. For fast 2D scanning, a continuous motor movement was implemented. We present details of the cryogenic sample environment and of the cryo-transfer system as key instrumentation that allows to protect the samples and to avoid any recrystallization of amorphous ice. We analyzed cryogenically fixed HeLa cells as a readily expandable cell line derived from cervical cancer and as one of the most widely used cell lines in biology. ${ }^{34-36}$

\section{MATERIALS AND METHODS}

\section{A. Cell culture}

HeLa cells were cultured in DMEM (Gibco, USA) supplemented with $10 \%$ fetal bovine serum (Sigma Aldrich Chemie $\mathrm{GmbH}$, Germany) and $1 \%$ penicillin-streptomycin (Gibco, USA) at $37^{\circ} \mathrm{C}$ in a humidified atmosphere with $5 \% \mathrm{CO}_{2}$ using $\mathrm{T}-25$ cell culture flasks (Sarstedt AG \& Co, Germany). The 7500-10 000 cells were split and seeded onto $\mathrm{SiN}_{\mathrm{x}}$ membranes on a single crystalline Si support (Si frame size $5 \times 5 \mathrm{~mm}$, frame thickness $200 \mu \mathrm{m}, \mathrm{SiN}_{\mathrm{x}}$ membrane size $1.5 \times 1.5 \mathrm{~mm}$ or $1 \times 1 \mathrm{~mm}$ in the center of the substrate, membrane thickness $500 \mathrm{~nm}$, Silson Ltd., only cells on the membrane were imaged) and allowed to grow for 12-16 h.

\section{B. Microscopy and cryo-fixation}

$\mathrm{SiN}_{\mathrm{x}}$ membranes with HeLa cells were imaged using a Zeiss Axio Observer Z1 (Zeiss Microscopy GmbH, Germany) prior to cryogenic fixation. Immediately after microscopy, the $\mathrm{SiN}_{\mathrm{x}}$ membranes were rinsed with PBS (Gibco, Cat No. 18912-014), blotted with cellulose paper (Whatman grade No. 1), plunge frozen into an ethane-propane mixture, ${ }^{32}$ and stored in liquid nitrogen until $\mathrm{x}$-ray fluorescence measurements were performed. ${ }^{37,38}$ The key step during cryo fixation is rapid freezing to cool the sample to $\approx 80 \mathrm{~K}$ as quickly as possible to allow the formation of vitreous ice that is free of crystallites. Therefore, the membrane is connected to a linear slider and quickly injected into an ethane-propane mixture and rapidly cooled down. ${ }^{38}$

\section{Cryogenic x-ray microprobe setup at P06, Petra III, DESY}

The x-ray microprobe fluorescence measurements on cryogenically fixed cells were carried out at the microprobe branch of the P06 beamline of PETRA III $^{39}$ using a cryogenic sample environment equipped with a cryogenic sample holder to maintain the sample temperature at $140 \mathrm{~K}$. The chamber had a base pressure of $10^{-8}$ mbar and the $\mathrm{x}$-rays entered the chamber through a Kapton window. The focus of the $\mathrm{KB}$ system of the beamline was $600 \times 500 \mathrm{~nm}^{2}$ at a photon energy of $13 \mathrm{keV}$. The fluorescence signal was detected by using a Vortex-EM450 silicon drift detector with a $50 \mathrm{~mm}^{2}$ active area and covered with an ultrathin $(1 \mu \mathrm{m})$ polymer window (Hitachi High-Technologies Science America, Inc.). The detector was positioned at an angle of $13^{\circ}$ to the sample surface plane, and as the exciting beam impinged at normal incidence, the angle between the beam and the detector was $77^{\circ}$. Because of spatial constraints due to the bulky sample stage, the distance from the sample to the detector was approximately $10 \mathrm{~mm}$, which limited the solid detection angle to $0.066 \mathrm{sr}$. The sample holder [Fig. 1(b)] was custom built out of copper. Due to its solid construction, it maximized the heat capacity, which maintained the temperature of the cryosamples at $130 \mathrm{~K}$ during transfer into the cryochamber and prevented ice crystallization. To fix the frozen silicon nitride samples, the shuttle was immersed in liquid nitrogen, the silicon nitride membrane was slid into the small gap on top of the sample holder, and the smaller steel part was screwed against the copper sample holder.

The samples were scanned in a horizontal/vertical direction normal to the beam using a continuous scanning scheme. The horizontal, fast axis was continuously scanned at a velocity of $5 \mu \mathrm{m} / \mathrm{s}$. Using the encoder signal of the stage, XRF spectra were acquired across a distance of $500 \mathrm{~nm}$ for $100 \mathrm{~ms}$ using an Xspress 3 pulse counter (Quantum detectors Ltd). When a line scan was finished, the turning point for the scanning motion was located outside of the scan window so that the stage returned to a steady motion prior to reinitiation of the data acquisition. The scan duration was $2.5 \mathrm{~h}$ for an area of $360 \times 45 \mu \mathrm{m}^{2}$. The fluorescence signal was normalized to the $\mathrm{I}_{0}$ signal recorded in front of the XRF experiment by an ionization chamber and according to the encoder position 
a

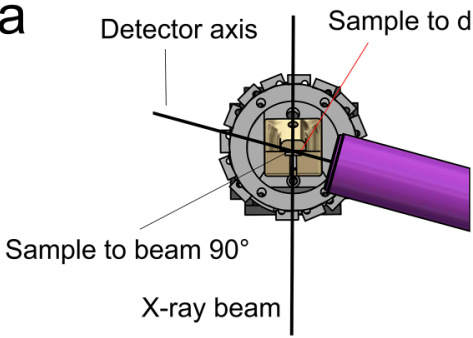

b

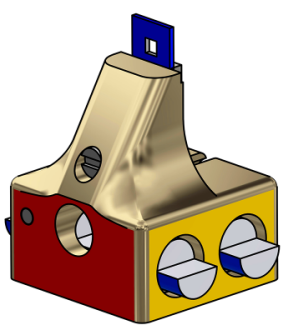

a

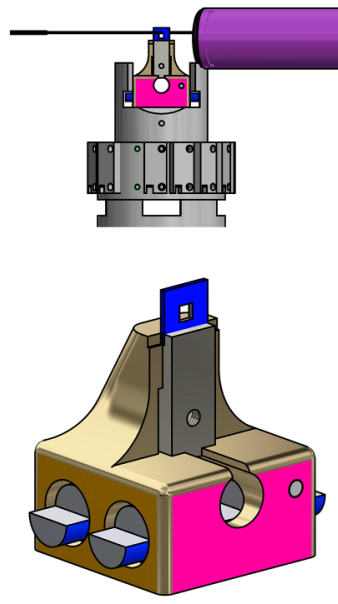

b

FIG. 1. (a) Setup of the sample environment in the vacuum chamber from above and from the front. Beam axis and detector axes are indicated by the lines. The design of the detector and the sample platform prevents short detector to sample distances. (b) Sample holder with $\mathrm{SiN}_{\mathrm{x}}$ membranes as a sample holder (blue). Within the outer $\mathrm{Si}$ frame, a $\mathrm{SiN}_{\mathrm{x}}$ membrane with a thickness of $500 \mathrm{~nm}$ was located (shown here transparent).

converted into a Cartesian coordinate grid. The individual fluorescence spectra were fitted by peak deconvolution using PyMCA software, ${ }^{40}$ which enables a fast batch XRF fitting and provides the concentrations of the detected elements based on the semiquantitative fundamental parameter method.

\section{RESULTS}

In order to analyze the biological samples by the $-x$-ray microprobe fluorescence method, the samples were first cryogenically fixed and then kept under vitrified conditions until the measurements were done. The plunge freezing process is shown schematically in Fig. 2(a) (1-3). First, $\mathrm{SiN}_{\mathrm{x}}$ membranes were immersed into the cell growth medium containing a suspension of the HeLa cells. In the second step, the $\mathrm{SiN}_{\mathrm{x}}$ membranes were removed from the cell media, rinsed with phosphate buffered saline (PBS), and the remaining liquid was blotted with filter paper. In the last step, the membrane with the remaining liquid was plunged into a liquid ethane-propane mixture. ${ }^{37,41}$ The ethane-propane mixture enables the phase transition from liquid to amorphous ice, while avoiding ice crystal formation. The challenge in the cryopreparation process is to obtain an amorphous ice layer on the membrane surface that is thick enough to embed and protect the cells and thin enough to minimize absorption and background signal contribution to the XRF spectra. Absorption is particularly relevant if light elements with low $-\mathrm{X}$-ray fluorescence energies are investigated. After plunge freezing, the samples were stored in liquid nitrogen until the start of the experiment. Prior to the experiment, the samples were mounted on the precooled sample holder [Fig. 1(b)], while keeping the sample and the sample holder under
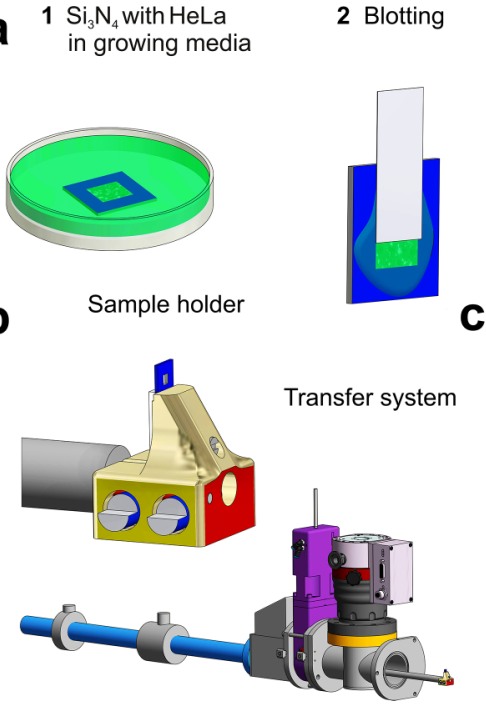

c

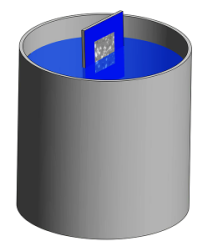

Sample environment

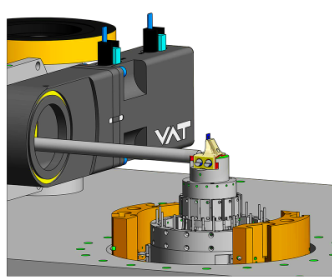

FIG. 2. (a) Cryogenic workflow including cell culture (1), blotting (2), and plunge freezing (3). (b) Sample holder with a $\mathrm{SiN}_{\mathrm{x}}$ membrane mounted on a transfer arm. (c) Sample holder after transfer into a cryo-vacuum chamber. The sample holder is placed on an X-, Y-, Z-stage, which enables the positioning and scanning of the sample through an $\mathrm{X}$-ray beam and a detector.

liquid nitrogen throughout the process. The sample holder was then picked up by the transfer rod [Fig. 1(b)], pulled back into the transfer system, evacuated, and transferred under vacuum into the vacuum chamber [Fig. 2(c)]. Mainly, samples with a size of $5 \times 5 \mathrm{~mm}^{2}$ (membrane window width $1.5 \times 1.5 \mathrm{~mm}, 500 \mathrm{~nm}$ thin $\mathrm{SiN}_{\mathrm{x}}$ windows) were used, but the system could also accommodate larger samples of $7.5 \times 7.5 \mathrm{~mm}^{2}$ (with $5 \times 5 \mathrm{~mm}, 500 \mathrm{~nm}$ windows). The transfer system (supplementary material $1^{65}$ ) and the vacuum chamber (supplementary material $2^{65}$ ) were equipped with a cooling system that kept the sample temperature at $-130{ }^{\circ} \mathrm{C}$ during the sample transfer and throughout the measurement. This sample preparation method and the vacuum-cryo system enabled the preservation of the distribution and the elemental content in the sample.

The complete sample transfer took about 30 min and included mounting the sample on the sample holder, evacuating the transfer system, and transferring it into the vacuum chamber. To locate the desired cells on the sample, it was imaged with a light microscope before the XRF experiment to determine suitable cell containing regions of interest (ROIs) for the measurements. After the sample transfer, a transmission scan was performed to locate the edges of the $\mathrm{SiN}_{\mathrm{x}}$ membrane and to determine the center of the membrane. Using the light microscopy images recorded prior to the beamtime, the coordinates of the sample ROI can be determined using an IMAGEJ script. This makes it possible to precisely locate positions on the sample in a short time. For accurate quantification, particularly for the light elements, a knowledge of ice thickness is essential. Here, the ice thickness was calculated by two different techniques. First, a standard transmission method was employed using 
the attenuation of the exciting beam when it passed through the sample. ${ }^{42}$ This method yielded an ice thickness of $40 \mu \mathrm{m}$. The drawback of this technique is that liquid on the back of the sample (unblotted side) contributes to the measurement, which leads to an overestimation of the relevant ice thickness between cell and detector. In order to restrict the measurement to the thickness of the ice layer on top of the silicon nitride membrane, the $\mathrm{Si}-\mathrm{K}_{\alpha}-\mathrm{x}$-ray fluorescent emission line $(\mathrm{E}=1.739 \mathrm{keV})$ from an empty membrane was compared with the signal when it passed through the thin ice layer. ${ }^{43}$ Due to the low emission energy of $\mathrm{Si}$, this method is highly sensitive to ice thickness. We measured an attenuation of the Si-K fluorescence of $30 \%$ from which an ice thickness of approx. $4 \mu \mathrm{m}$ was calculated. This value was below the number determined from the transmission experiment, which is most likely due to the ice layer present at the unblotted back of the sample. An ice thickness of $4 \mu \mathrm{m}$ was used to account for the energy dependent attenuation of the fluorescent signals in the sample. We have to note at this point that $4 \mu \mathrm{m}$ is the thickness of ice under the mean take-off angle of the photons toward the detector $\left(\approx 77^{\circ}\right.$ with respect to the surface normal); thus, the true ice thickness along the normal is slightly thinner and in the order of $0.9 \mu \mathrm{m}$. For correction purposes, the determined value of $4 \mu \mathrm{m}$ was used as the analyzed photons had to pass through this ice thickness when propagating to the detector.

To demonstrate the capabilities of the P06 cryo -endstation, we analyzed the elemental composition of the frozen-hydrated HeLa cells. Phase contrast light microscopy images were used to locate the regions of interest on the $\mathrm{SiN}_{\mathrm{x}}$ membrane [Fig. 3(a)]. We were able to detect potassium and chloride which have a high diffusion coefficient and are usually strongly affected by fixation and washing steps [Fig. 3(b)]. Additionally, we detected zinc in the HeLa cells. Particularly potassium showed a strong signal compared with other conventional fixation procedures ${ }^{33}$ which, depending on the precise preparation protocol, might be completely removed from the cells during the fixation process. The chloride signal revealed lower intracellular densities than the buffer in the surrounding amorphous ice matrix as a result of the active osmoregulation of the cells. Similar to potassium, chloride can also be strongly affected by chemical fixation and drying of samples. ${ }^{33}$

Figure 3(b) additionally contains intensity profiles through differently imaged HeLa cells. Cells with rather spherical shapes showed relatively high levels of potassium, while flattened HeLa cells showed slightly lower values. This result was expected since 2D XRF scanning measures the total "projected" area. Also, variations in the metal densities throughout the cells were expected, particularly for the cell nucleus. As shown in Fig. 4(b), the metal distributions in the HeLa cells are further analyzed using histograms of the intracellular potassium levels, and two types of distributions are identified. In the upper panel of Fig. 4(b), the intensity distribution of a cell with a rather spherical appearance and in the bottom panel the distribution of a flat cell are shown in comparison. In both cases, only the cell itself without any background was analyzed. Local maxima in the occurrence are centered around 105 and 120. It becomes clearly visible that the high intensities at around 165 counts show a much higher occurrence in the spherical cells than in the elongated and well spread ones (the results were verified with those of the other cells in Fig. 3).
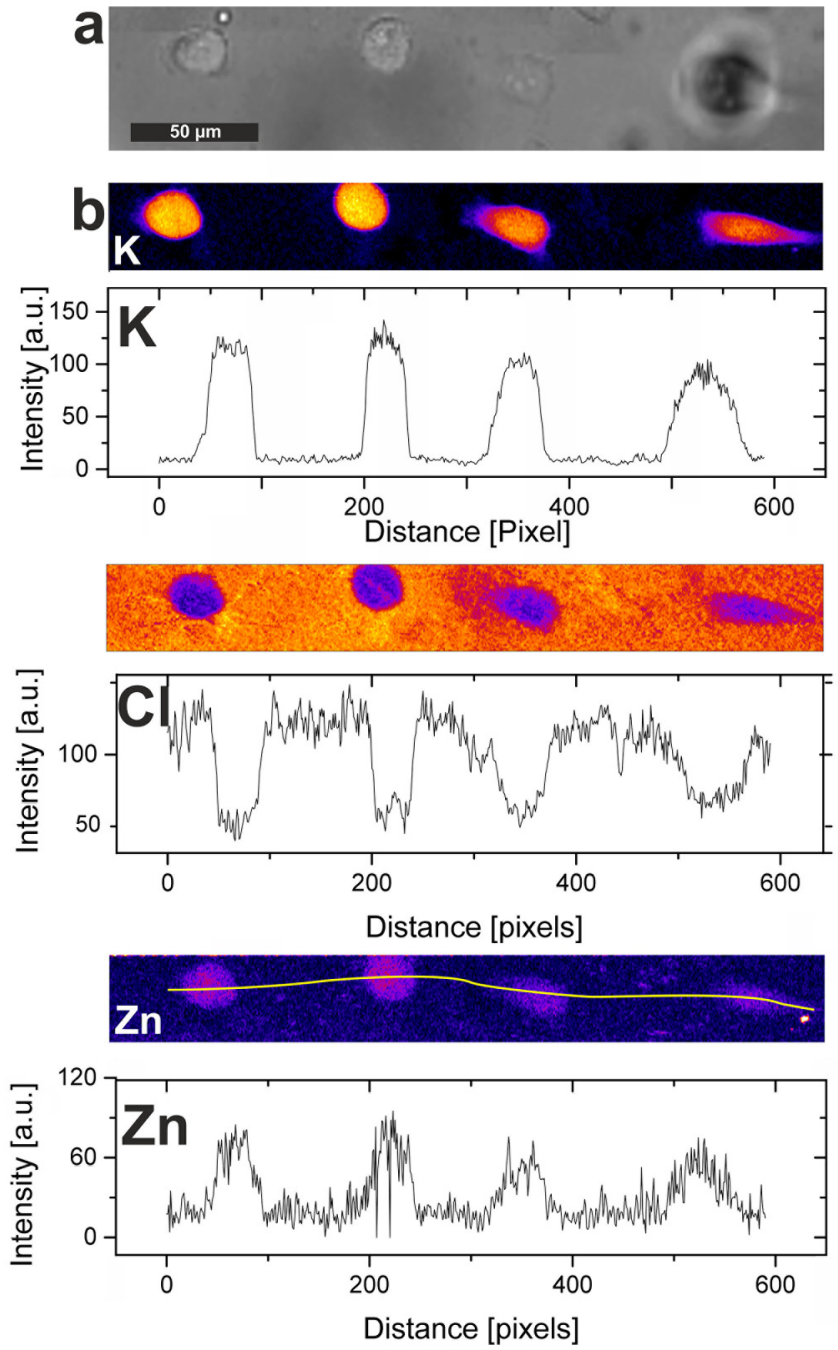

FIG. 3. (a) Phase contrast microscopy images of the cells prior to cryopreparation. (b) Micro -x-ray fluorescence analysis of HeLa cells recorded at the P06 microprobe beamline (Petra III). X-ray fluorescence measurements were recorded at $13 \mathrm{keV}$ with a $600 \times 500 \mathrm{~nm}^{2}$ focal spot size. Potassium and zinc could be detected inside the cells as well as the lower density of chloride inside the cells compared with the surrounding buffer. The line profiles show the intensity distribution across several cells along the yellow line exemplarily shown in the $\mathrm{Zn}$ map.

In addition, we estimated the area mass densities of different intracellular elements by making a comparison with a reference sample (thin film XRF reference sample, RF17-200-S4218-41, AXO, Dresden). The reference sample was measured with the same beam and scan parameters as the HeLa cells. The estimated element areal densities were corrected for the ice thickness of $4 \mu \mathrm{m}$ as determined by the Si-K $\alpha$ method. ${ }^{43}$ As mentioned above, $4 \mu \mathrm{m}$ is the thickness of ice under the mean take-off angle of the photons toward the detector, and the true ice thickness along the normal is 

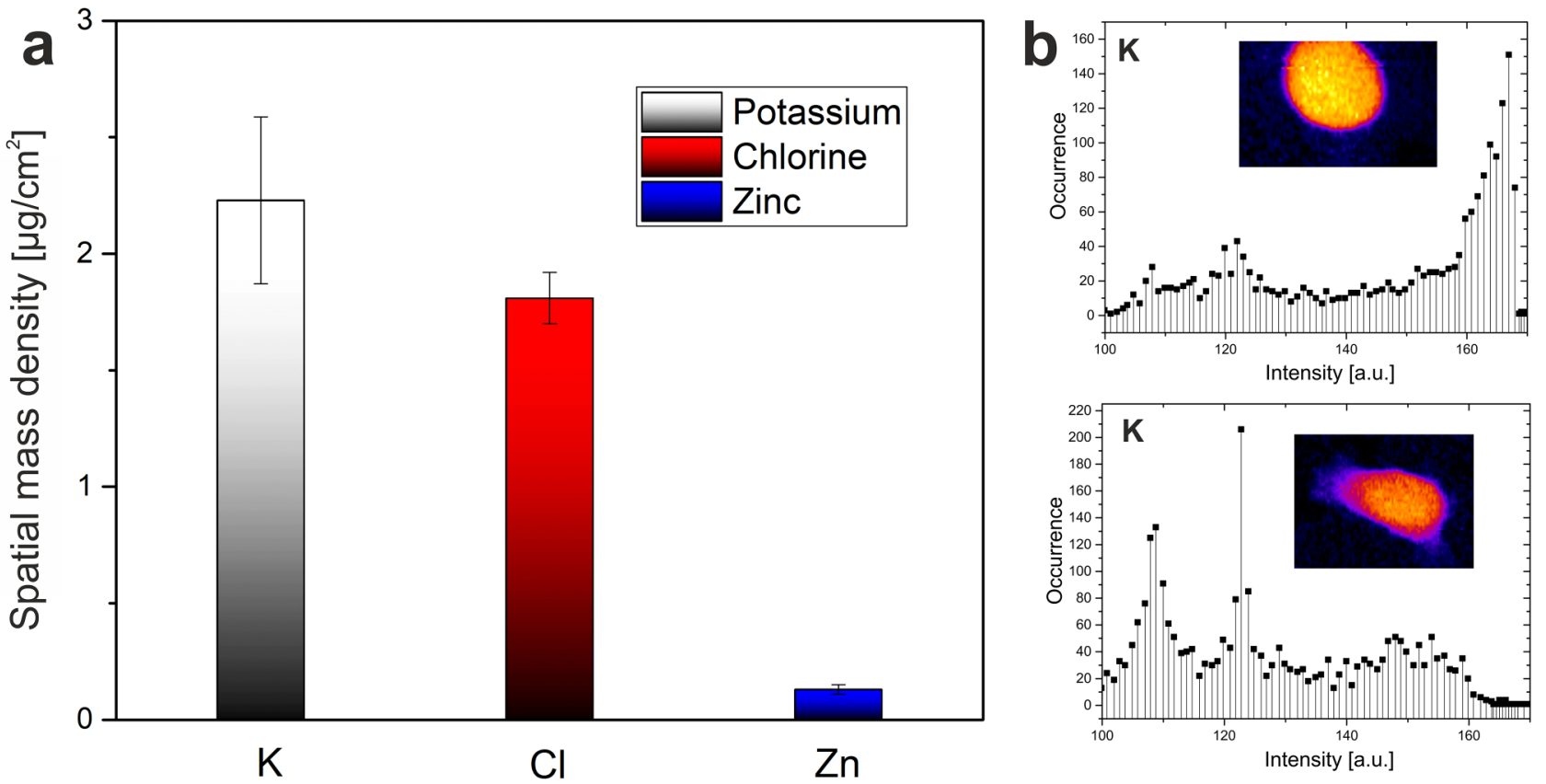

FIG. 4. (a) Average spatial mass densities of $\mathrm{K}, \mathrm{Cl}$, and $\mathrm{Zn}$ expressed in $\mu \mathrm{g} / \mathrm{cm}^{2}$. (b) Intensity distribution of potassium inside HeLa cells represented as histograms of the occurrence of the intensity values. Two types of distribution are discernible: in cells with a spherical shape, the intensity distribution has higher values, whereas lower values are found for flat, well spread cells.

slightly thinner and in the order of $0.9 \mu \mathrm{m}$. For correction, an ice thickness of $4 \mu \mathrm{m}$ through which the analyzed photons have to pass when they propagate to the detector is considered. In Table I, the obtained spatial mass densities of potassium, chloride, and zinc are summarized and plotted as a bar graph in Fig. 3(a). For potassium, we obtained a spatial mass density of $2.23 \pm 0.35 \mu \mathrm{g} / \mathrm{cm}^{2}$ $\left(0.057 \mu \mathrm{mol} / \mathrm{cm}^{2}\right)$, for zinc $0.13 \pm 0.02 \mu \mathrm{g} / \mathrm{cm}^{2}\left(0.0019 \mu \mathrm{mol} / \mathrm{cm}^{2}\right)$, and $1.81 \pm 0.11 \mu \mathrm{g} / \mathrm{cm}^{2}\left(0.051 \mu \mathrm{mol} / \mathrm{cm}^{2}\right)$ for chloride. For potassium ( $92 \%$ higher) and zinc (67\% higher), the obtained values were higher than in the surrounding medium. Thus, the mass densities resembled the ion concentrations within the cells. In the case of chloride, the signal was weaker (55\%) than in the surrounding medium. This indicates that a major part of the signal came from the medium and the cell was depleted in chloride compared with the surrounding ice matrix. As the precise thickness of the cell was not known, the intracellular chloride levels could not be accurately

TABLE I: Average spatial mass densities of detected elements in the regions where HeLa cells were adhered. Quantities are expressed in $\mu \mathrm{g} / \mathrm{cm}^{2}$. Errors represent the standard deviation.

\begin{tabular}{cc}
\hline \hline & Spatial mass density $\left(\mu \mathrm{g} / \mathrm{cm}^{2}\right)$ \\
\hline Potassium & $2.23 \pm 0.35$ \\
Chloride & $1.81 \pm 0.11$ \\
Zinc & $0.13 \pm 0.02$ \\
\hline
\end{tabular}

calculated, and the values in Table I do not reflect the intracellular chloride concentration.

\section{DISCUSSION}

The newly implemented cryogenic instrument at the P06 beamline at PETRA III, DESY has been described in detail and is demonstrated to be an appropriate cryo-XRF nanoanalysis tool for the determination of the spatial densities and the distribution of elements in the frozen hydrated cellular samples. We used a relatively large $\mathrm{KB}$ focus of $600 \times 500 \mathrm{~nm}^{2}$ in order to be able to analyze sufficiently large areas and correlate our results with phase contrast microscopy images. Among the advantages of cryo-XRF is the possibility of determining the local distribution and concentration of elements in the cell without chemical staining and fixation. There are several other methods available for the estimation of trace element concentrations in cells and tissue such as electrochemical analysis, ${ }^{44,45}$ mass spectrometry, ${ }^{46} \mathrm{x}$-ray emission induced by electron beam excitation (SEM-EDX), ${ }^{47,48}$ and particle or proton induced $\mathrm{x}$-ray emission. ${ }^{48-51}$ The applied method of $\mathrm{x}$-ray excitation, in conjunction with $\mathrm{x}$-ray detection, stands out due to a high penetration depth in conjunction with a good spatial resolution for an analysis of cryofixed bulk materials.

As a model system to demonstrate the applicability of the new techniques, adherent HeLa cells on SiNx membranes were investigated in a plunge frozen, vitrified state. We noticed a slight variability in the shape of the cells which might have been caused by the cells being in different stages in the cell cycle. As the cells were not 
synchronized, the different physiological states of the cells became apparent due to their shapes, and some of the cells were more spherical than others. Different reasons could be attributed to their different shapes. Either the cells were not well adhered, they underwent apoptosis, ${ }^{52}$ or they were adhered just before cell division. ${ }^{53}$ Apoptosis was highly unlikely as this process would severely impact the element composition (e.g., a decrease in potassium concentration in the cells due to dysfunctional ion pumps ${ }^{54}$ ). Also, very weakly adherent cells would have been washed off the surface during the rinsing steps, so some different stage in the cell cycle was the most likely reason for the cells having different shapes. As well spread cells are usually flatter than cells that roll up prior to division, the projected total ion content is smaller in well spread cells, which can explain the lower ion densities found in XRF.

The detected potassium and chloride are commonly occurring and physiologically important elements in cells. Altered potassium levels are frequently associated with different disorders. Waters et $a l^{23}$ could show that mutated $\mathrm{K}^{+}$channels led to disturbed $\mathrm{K}^{+}$transport. ${ }^{23}$ Also in neurodegenerative diseases such as Huntington, ${ }^{24}$ Alzheimer, ${ }^{25}$ and Parkinson, ${ }^{26,27} \mathrm{~K}^{+}$- exchange is reduced. Because of high diffusion rates, it is apparent that only in situ techniques or cryogenic preparation are effective as most other fixation or staining techniques can alter the $\mathrm{K}^{+}$concentrations. ${ }^{33}$ In the literature, different intracellular concentrations of potassium have been reported using XRF: in high-pressure frozen, cryosubstituted human neutrophils, area densities of $29.4 \mu \mathrm{g} / \mathrm{cm}^{2}$ of $\mathrm{K}$ were detected. ${ }^{13}$ In an XRF experiment using freeze dried, single PC12 cells, area densities of $\mathrm{K}$ of $0.065 \mu \mathrm{g} / \mathrm{cm}^{2}$ and $0.015 \mu \mathrm{g} / \mathrm{cm}^{2}$ were measured. ${ }^{55}$ While human neutrophils were obtained from a donor, PC12 cells were cultivated in a growth medium. In an XRF analysis of fixed 22Rv1 cells, potassium concentrations of $0.125 \mu \mathrm{g} / \mathrm{cm}^{2}$ were reported. ${ }^{56}$ In this work, potassium levels of $2.23 \pm 0.35 \mu \mathrm{g} / \mathrm{cm}^{2}$ were measured in the investigated HeLa cells, which are within the range of the literature data. ${ }^{13,55,56}$ Deviations between the different measurements could arise from differences in the quantification approach (e.g., standards used), investigated cell type, measurement procedure, growth environment of the cells, or the (cryogenic) fixation procedure. To obtain homogeneous distributions of potassium, cryo-fixation seemed to be particularly important, especially when compared with chemical fixation ${ }^{13}$ and lyphopilization. ${ }^{55}$

While potassium showed a strongly enhanced signal inside the cells, the intracellular chloride density was depleted compared with the chloride levels in the surrounding vitrified buffer as the background. This depleted chloride density, together with the enhanced potassium levels inside the cells, indicated that the cells were still viable and that ion transport was still taking place. Chloride transport in cells is regulated by $\mathrm{Cl}^{-}$- channels, which are involved in the regulation of electrical excitability, ionic homeostasis, and cell volume regulation. ${ }^{57}$ Disturbed or dysfunctional cell volume control can have severe consequences for cells, including apoptosis. ${ }^{57}$ Due to the fact that potassium is the dominating intracellular ion, the $\mathrm{Cl}^{-}$channels serve to achieve ionic homeostasis and transport of $\mathrm{Cl}^{-}$ions outside cells. As mentioned above, a further quantification would require a precise knowledge of the local thicknesses of the cells and of the surrounding electrolyte dominating the signal, which is currently not accessible. Similar to potassium, chloride is an ion with a high diffusion rate and is, thus, susceptible to diffusion before or during fixation, which became obvious for chemically fixed cells in which chloride was not detectable. $^{35}$

Another element that was detected within the HeLa cells was $\mathrm{Zn}$. The homeostasis of $\mathrm{Zn}^{58}$ is disturbed in neurodegenerative disorders such as Huntington, Alzheimer, and Parkinson. ${ }^{59,60} \mathrm{Zn}$ is a part of CuZn superoxide dismutase (SOD) and catalyzes the reaction from superoxide to hydrogen peroxide. Superoxides are present in all aerobic cells but can also lead to oxidative damage particularly if the CuZn-SOD function is disturbed. ${ }^{61} \mathrm{Zinc}$ is also responsible for the activity of several enzymes and supports DNA binding, e.g., in $\mathrm{Zn}$ finger proteins. ${ }^{41}$ In addition, it is able to protect proteins from oxidative damage. ${ }^{62}$ The concentration of zinc can be determined by atomic absorption spectroscopy (AAS) ${ }^{63}$ and immunofluorescence microscopy. ${ }^{64}$ Immunofluorescence microscopy reveals local accumulations of zinc, but accurate quantifications are barely possible. AAS provides information on average $\mathrm{Zn}$ concentrations in a larger sample size, but samples are destroyed after measurement and spatial resolution are not accessible. In the case of the investigated HeLa cells, we estimated a concentration of $0.13 \pm 0.02 \mu \mathrm{g} / \mathrm{cm}^{2}$ for zinc ( $\mathrm{Zn}$ background concentration $0.047 \mu \mathrm{g} / \mathrm{cm}^{2}$ ). In the literature, different values are reported; e.g., in cryosubstituted human neutrophils, $24.4 \mu \mathrm{g} / \mathrm{cm}^{2}$ were detected, ${ }^{13}$ while in NIH/3T3 cells prepared by using different fixation protocols, spatial densities of up to $0.05 \mu \mathrm{g} / \mathrm{cm}^{2}$ were measured. ${ }^{33}$ The values obtained in our measurements of $0.13 \mu \mathrm{g} / \mathrm{cm}^{2}$ (Table I) for zinc are in the same range as the literature reports. It seems as if the reported literature values are slightly less variable for intracellular $\mathrm{Zn}$ levels when compared with the potassium levels, probably because it is frequently bound to proteins, and, thus, its concentration is less affected by sample preparation, even if noncryogenic sample preparation techniques are used.

\section{SUMMARY AND CONCLUSION}

We presented details of the cryogenic - $\mathrm{x}$-ray fluorescence chamber at the P06 beamline at PETRA III including the sample transfer system and the data acquisition concept. As an example, we discussed results obtained on intracellular ion concentrations in cryogenically prepared HeLa cells. A continuous scanning scheme, in conjunction with a new sample holder design, enables quick data acquisition and the determination of intracellular ion levels. The vacuum environment was necessary to maintain the quality of the cryogenic samples and ensured effective detection of the XRF signal. The data revealed the elemental area densities "in cellulo" and $2 \mathrm{D}$ elemental maps were obtained with high spatial resolution that could directly be compared with phase-contrast and fluorescence microscopy images. The local accumulation of elements could be visualized and quantitatively analyzed. A great strength compared with alternate chemically sensitive imaging techniques, e.g., based on dyes is that several metals, such as $\mathrm{K}, \mathrm{Cl}$, and $\mathrm{Zn}$, can be detected simultaneously, which is of great value for quantitative comparisons. In particular, the correlation with confocal microscopy using histologic stains or cells expressing fluorescent markers appears to be very interesting for the future. As fixation steps can strongly affect elemental intracellular concentrations, sample preparation procedures are critical. Here, cryo-protected samples provide 
results closest to the native state of the samples. The technical implementations at the P06 beamline enable future correlative, element-sensitive cryogenic nanoanalysis on cellular material. Smaller foci, like those that are easily obtainable by the upcoming Petra IV upgrade, will even allow focusing on elemental distributions within organelles or other intracellular compartments. Beyond cells, the setup is also suitable for investigating samples such as tissue, plants, bacteria, and hydrated organic or inorganic samples.

\section{ACKNOWLEDGMENTS}

We acknowledge the financial support of the BMBF project (Nos. 05K16PC1 and 05K19PC2) and the Cluster of Excellence RESOLV (EXC 1069). We acknowledge DESY (Hamburg, Germany), a member of the Helmholtz Association HGF, for the provision of experimental facilities. B.d.S. acknowledges his grant for a long stay abroad from the Fund for Scientific Research Flanders (FWO Vlaanderen, www.fwo.be, Grant No. V.4.114.10.N.00). Parts of this research were carried out at PETRA III, and we would like to thank the staff of the P06 beamline for assistance. The research leading to this result was supported by the project CALIPSOplus under the Grant Agreement No. 730872 from the EU Framework Program for Research and Innovation HORIZON 2020.

\section{DATA AVAILABILITY}

The data that support the findings of this study are available from the corresponding author upon reasonable request.

\section{REFERENCES}

${ }^{1}$ U. E. A. Fittschen and G. Falkenberg, Spectrochim. Acta Part B 66, 567 (2011). ${ }^{2}$ M. J. Pushie, I. J. Pickering, M. Korbas, M. J. Hackett, and G. N. George, Chem. Rev. 114, 8499 (2014).

${ }^{3}$ M. Shimura et al., Cancer Res. 65, 4998 (2005).

${ }^{4}$ S. Vogt, L. A. Finney, I. F. Musgrave, J. B. Aitken, H. H. Harris, M. D. de Jonge, D. L. Howard, C. M. Weekley, and D. J. Paterson, Biochemistry 50, 1641 (2011).

${ }^{5}$ A. C. Niehoff et al., Anal. Chim. Acta 938, 106 (2016).

${ }^{6}$ C. Sanchez-Cano, I. Romero-Canelón, Y. Yang, I. J. Hands-Portman, S. Bohic, P. Cloetens, and P. J. Sadler, Chemistry 23, 2512 (2017).

${ }^{7}$ J. Z. Zhang, N. S. Bryce, A. Lanzirotti, C. K. J. Chen, D. Paterson, M. D. De Jonge, D. L. Howard, and T. W. Hambley, Metallomics 4, 1209 (2012).

${ }^{8}$ J. B. Waern, H. H. Harris, B. Lai, Z. Cai, M. M. Harding, and C. T. Dillon, J. Biol. Inorg. Chem. 10, 443 (2005).

${ }^{9}$ M. D. De Jonge et al., Proc. Natl. Acad. Sci. U.S.A. 107, 15676 (2010).

${ }^{10}$ J. Mahamid et al., Proc. Natl. Acad. Sci. U.S.A. 107, 6316 (2010).

${ }^{11}$ J. Deng et al., Proc. Natl. Acad. Sci. U.S.A. 112, 2314 (2015).

${ }^{12}$ X. Huang et al., Phys. Rev. Lett. 103, 198101 (2009).

${ }^{13}$ B. De Samber, M. J. Niemiec, B. Laforce, J. Garrevoet, E. Vergucht, R. De Rycke, P. Cloetens, C. F. Urban, and L. Vincze, PLoS One 11, e0165604 (2016).

${ }^{14}$ S. Chen et al., AIP Conf. Proc. 1696, 020028 (2016).

${ }^{15}$ L. Vincze, B. Vekemans, F. E. Brenker, G. Falkenberg, K. Rickers, A. Somogyi, M. Kersten, and F. Adams, Anal. Chem. 76, 6786 (2004).

${ }^{16}$ B. Kanngießer, W. Malzer, M. Pagels, L. Lühl, and G. Weseloh, Anal. Bioanal. Chem. 389, 1171 (2007)

${ }^{17}$ T. Senkbeil, T. Mohamed, R. Simon, D. Batchelor, A. Di Fino, N. Aldred, A. S. Clare, and A. Rosenhahn, Anal. Bioanal. Chem. 408, 1487 (2016).

${ }^{18}$ C. G. Schroer, J. Tuemmler, T. F. Guenzler, B. Lengeler, W. H. Schroeder, A. J. Kuhn, A. S. Simionovici, A. A. Snigirev, and I. Snigireva, in Penetrating
Radiation Systems and Applications II, edited by F. P. Doty, H. B. Barber, H. Roehrig, and E. J. Morton (SPIE, 2000), p. 287.

${ }^{19}$ M. D. de Jonge and S. Vogt, Curr. Opin. Struct. Biol. 20, 606 (2010).

${ }^{20} \mathrm{~B}$. Laforce et al., Anal. Chem. 89, 10617 (2017).

${ }^{21}$ S. Corezzi, L. Urbanelli, P. Cloetens, C. Emiliani, L. Helfen, S. Bohic, F. Elisei, and D. Fioretto, Anal. Biochem. 388, 33 (2009).

${ }^{22}$ S. Roudeau, A. Carmona, L. Perrin, and R. Ortega, Anal. Bioanal. Chem. 406, 6979 (2014).

${ }^{23}$ M. F. Waters et al., Nat. Genet. 38, 447 (2006).

${ }^{24}$ M. A. Ariano et al., J. Neurophysiol. 93, 2565 (2005).

${ }^{25}$ E. Angulo, V. Noe, V. Casado, J. Mallol, T. Gomez-Isla, C. Lluis, I. Ferrer, C. J. Ciudad, and R. Franco, J. Neurochem. 91, 547 (2004).

${ }^{26}$ J. A. Santiago and J. A. Potashkin, Trends Mol. Med. 19, 176 (2013).

${ }^{27}$ C. Tian, R. Zhu, L. Zhu, T. Qiu, Z. Cao, and T. Kang, Chem. Biol. Drug Des. 83, 1 (2014).

${ }^{28}$ J. Chwiej, M. Szczerbowska-Boruchowska, M. Lankosz, S. Wojcik, G. Falkenberg, Z. Stegowski, and Z. Setkowicz, Spectrochim. Acta Part B 60, 1531 (2005).

${ }^{29}$ S. Matsuyama et al., X-Ray Spectrom. 39, 260 (2010).

${ }^{30}$ M. J. Hackett et al., Analyst 136, 2941 (2011).

${ }^{31}$ J. Makjanic and F. Watt, Nucl. Instrum. Methods Phys. Res. B 150, 167 (1999).

${ }^{32}$ S. Kasas, G. Dumas, G. Dietler, S. Catsicas, and M. Adrian, J. Microsc. 211, 48 (2003).

${ }^{33}$ Q. Jin et al., J. Microsc. 265, 81 (2017).

${ }^{34}$ C. F. T. Mattern and W. A. Daniel, Virology 26, 646 (1965).

${ }^{35}$ J. H. Kim, Cancer Res. 32, 323 (1972).

${ }^{36}$ P. N. Rao, M. L. Smith, S. Pathak, R. A. Howard, and J. L. Bear, J. Natl. Cancer Inst. 64, 905 (1980).

37. M. Plitzko and W. Baumeister, in Science of Microscopy, edited by P. W. Hawkes and J. C. H. Spence (Springer, New York, NY, 2007), pp. 535-604. ${ }^{38}$ T. Gorniak and A. Rosenhahn, Z. Phys. Chem. 228, 1 (2014).

${ }^{39}$ C. G. Schroer et al., Detect. Assoc. Equip. 616, 93 (2010).

${ }^{40}$ V. A. Solé, E. Papillon, M. Cotte, P. Walter, and J. Susini, Spectrochim. Acta Part B 62, 63 (2007).

${ }^{41}$ D. J. Tate, M. V. Miceli, and D. A. Newsome, Free Radic. Biol. Med. 26, 704 (1999).

${ }^{42}$ B. De Samber et al., PLoS One 13, e0190495 (2018).

${ }^{43}$ C. Rumancev et al., J. Synchrotron Radiat. 27, 60 (2020).

${ }^{44}$ E. A. C. Macrobbie and J. Lettau, J. Membr. Biol. 56, 249 (1980).

${ }^{45}$ M. A. Moreno, C. Marin, F. Vinagre, and P. Ostapczuk, Sci. Total Environ. 229, 209 (1999).

${ }^{46}$ S. Scherzer et al., Proc. Natl. Acad. Sci. U.S.A. 112, 7309 (2015).

${ }^{47}$ C. Can and W. Jianlong, Appl. Microbiol. Biotechnol. 79, 293 (2008).

${ }^{48}$ G. J. Naga Raju et al., Appl. Radiat. Isot. 64, 893 (2006).

${ }^{49}$ K. N. Devi, H. N. Sarma, and S. Kumar, Nucl. Instrum. Methods Phys. Res. Sect. B 266, 1605 (2008).

${ }^{\mathbf{5 0}}$ M. L. Carvalho, T. Magalhães, M. Becker, and A. von Bohlen, Spectrochim. Acta Part B 62, 1004 (2007).

${ }^{51}$ Z. Karcioglu, M. Sarper, H. Van Rinsvelt, J. Guffey, and W. Fink, Am. Cancer Soc. 42, 1330 (1978).

${ }^{52}$ F. M. Hughes and J. A. Cidlowski, Adv. Enzyme Regul. 39, 157 (1999).

${ }^{53}$ C. Cadart, E. Zlotek-Zlotkiewicz, M. Le Berre, M. Piel, and H. K. Matthews, Dev. Cell 29, 159 (2014).

${ }^{54}$ S. P. Yu, Prog. Neurobiol. 70, 363 (2003).

${ }^{55}$ E. Kosior, S. Bohic, H. Suhonen, R. Ortega, G. Devès, A. Carmona, F. Marchi, J. F. Guillet, and P. Cloetens, J. Struct. Biol. 177, 239 (2012).

${ }^{56}$ J. L. Wedding et al., Metallomics 9, 382 (2017).

${ }^{57}$ T. J. Jentsch, V. Stein, F. Weinreich, and A. A. Zdebik, Physiol. Rev. 82, 503 (2002). 
${ }^{58}$ M. C. Owen, D. Gnutt, M. Gao, S. K. T. S. Wärmländer, J. Jarvet, A. Gräslund, R. Winter, S. Ebbinghaus, and B. Strodel, Chem. Soc. Rev. 48, 3946 (2019).

${ }^{\mathbf{5 9}}$ S. Rivera-Mancía, I. Pérez-Neri, C. Ríos, L. Tristán-López, L. Rivera-Espinosa, and S. Montes, Chem. Biol. Interact. 186, 184 (2010).

${ }^{60}$ A. S. Pithadia and M. H. Lim, Curr. Opin. Chem. Biol. 16, 67 (2012).

${ }^{61}$ J. S. Valentine and P. J. Hart, Proc. Natl. Acad. Sci. U.S.A. 100, 3617 (2003).
${ }^{62}$ D. A. Newsome, M. V. Miceli, M. R. Liles, D. J. Tate, and P. D. Oliver, Prog. Retin. Eye Res. 13, 101 (1994).

${ }^{63}$ M. Zowczak, M. Iskra, L. Torliński, and S. Cofta, Biol. Trace Elem. Res. 82, 001 (2001).

${ }^{64}$ M. Lazarczyk, C. Pons, J.-A. Mendoza, P. Cassonnet, Y. Jacob, and M. Favre, J. Exp. Med. 205, 35 (2008).

${ }^{65}$ See supplementary material at https://doi.org/10.1116/6.0000593. 